\title{
PRÁTICAS DE INTEGRIDADE NO PROCESSO DE CAPTAÇÃO DE RECURSOS PELAS ORGANIZAÇÕES DO TERCEIRO SETOR
}

$\begin{array}{ll}\text { Recebido em } & 13.12 .2017 \\ \text { Aprovado em } & 19.12 .2017\end{array}$

\begin{abstract}
Albenice Correia de Melo
Mestre em Controladoria Empresarial, especialista tributária, advogada, contadora, perita contábil, mediadora judicial e extrajudicial, com mais de 15 anos de atuação na área contábil em empresas de vários segmentos, atualmente voltada à gestão de conflitos empresariais, dissoluções societárias, apuração de haveres, prestação de contas e consultoria nas áreas de compliance e educação corporativa como instrumentos de prevenção de litígios.

E-mail: albenici@hotmail.com

\section{Ana Lucia Fontes de Souza Vasconcelos}

Pós-Doutorado na Universidade de São Paulo/USP, Programa de Pós-Graduação em Controladoria e

Contabilidade da FEA/USP - PPGCC. Doutorado em Serviço Social pela Universidade Federal de Pernambuco - UFPE. Mestrado em Ciências Contábeis e Atuariais pela Pontifícia Universidade Católica de São Paulo/PUC/SP. Graduação em Ciências Contábeis pela Universidade Católica de Pernambuco/ Unicap (1989). Membro do Mestrado Profissional em Controladoria Empresarial (PPGCC) da Universidade Presbiteriana Mackenzie. E-mail:anafontes_ufpe@yahoo.com.br
\end{abstract}




\section{RESUMO}

As organizações que compõem o Terceiro Setor são aliadas do Estado no atendimento das necessidades públicas, e por essa razão desempenham papel relevante na sociedade. A captação de recursos nesses tipos de organizações é um dos principais componentes de gestão, visto não possuírem finalidade lucrativa, dependendo de recursos advindos de terceiros para a manutenção de suas atividades. Dentro do processo de captação de recursos, as organizações do terceiro setor ficam expostas aos mais variados riscos que podem comprometer a sua natureza jurídica e sustentabilidade. Mecanismos de controle interno são a resposta para abolir ou minimizar os riscos operacionais que as organizações dessa natureza têm de enfrentar no desempenho comum de suas atividades. O presente estudo, pautado em revisão bibliográfica acerca da dependência de recursos e de controles internos, buscou oferecer um modelo de Programa de Práticas de Integridade, formatado a partir da intervenção em uma organização, no qual há um dimensionamento dos riscos específicos voltados ao processo de captação de recursos para subsidiar as organizações do terceiro setor com informações específicas, de modo que possam operar de forma mais segura e atender aos aparatos legislativos aos quais estão sujeitas.

\section{PALAVRAS-CHAVE}

Captação de recursos. Terceiro Setor. Riscos operacionais. Práticas de integridade. 


\section{INTRODUÇÃO}

As notícias veiculadas na mídia indicam que a corrupção ainda faz parte da realidade brasileira, e o nível de percepção da população aumentou no último ano, de acordo com o ranking 2016 organizado pela Transparency International, em que o Brasil ocupa a $79^{a}$ posição entre 176 países, contra a $76^{\mathrm{a}}$ posição entre 168 países ocupada em 2015. Ainda de acordo com essa instituição, grandes corrupções prosperam em ambientes com configurações corrompidas. Casos como o da Petrobras e da Odebrecht no Brasil ou a saga do ex-presidente Viktor Yanukóvych na Ucrânia mostram como a colusão entre as empresas e os políticos absorve bilhões de dólares em receitas das economias nacionais, beneficiando poucos em detrimento de muitos. Esse tipo de grande corrupção sistêmica viola os direitos humanos, impede o desenvolvimento sustentável e alimenta a exclusão social.

Percebe-se, assim, que não é um fenômeno que ocorre somente no Brasil, tampouco uma característica própria da cultura brasileira, isso porque, com a ampliação das relações internacionais, seu alcance tem sido global. Assim, diante de tal realidade, o
Estado brasileiro vem buscando adotar práticas de prevenção e de combate à corrupção mediante a expansão e o fortalecimento de suas relações com outros países (MTFC, 2016, p. 4).

Nesse sentido, foram ratificadas pelo Brasil a Convenção Interamericana contra a Corrupção, a Convenção das Nações Unidas contra a Corrupção e a Convenção sobre o Combate da Corrupção de Funcionários Públicos Estrangeiros em Transações Comerciais Internacionais da Organização para a Cooperação e Desenvolvimento Econômico (OCDE).

\begin{abstract}
Em muitos ordenamentos jurídicos, as leis de combate à corrupção envolvendo o setor privado são referenciadas, em termos históricos, na Lei Americana Anticorrupção (The Foreign Corrupt Practices Act - FCPA), aprovada em 1977 e suas alterações. A FCPA é uma lei federal dos EUA que proíbe subornos a funcionários de governos estrangeiros e figuras políticas (GÓls; SANTOS; ROCHA, 2016, p. 233).
\end{abstract}

O Brasil seguiu a mesma esteira americana no que se refere à responsabilidade de empresários na gestão empresarial e na divulgação de informações financeiras, e 
em 2013 sancionou a Lei n. 12.846, também conhecida como a Lei Anticorrupção, que dispõe acerca da responsabilidade administrativa e civil de pessoas jurídicas pela prática de atos contra a administração pública, nacional ou estrangeira.

A Lei n. 12.846/2013 é expressa em afirmar que a responsabilidade imposta às pessoas jurídicas não exige prova de conduta culposa, sendo devida pela simples prática de ato contra a Administração Pública, configurando, assim, responsabilidade por culpa objetiva (MAGALHAES, 2013, p. 25).

Embora adote a responsabilidade objetiva em casos de condenação de uma organização, os mecanismos e os procedimentos internos de integridade adotados pela Lei Anticurrupção servirão para a dosimetria de sua pena, ou seja, ainda que os procedimentos internos não afastem a responsabilidade da organização, eles impactam na aplicação da pena.

[...] compreendendo, com louvor, o legislador federal que o combate à corrupção deve ser um constante, na busca de uma cultura que repudie atos corruptivos, previu que "a existência de mecanismos e procedimentos internos de integridade, auditoria e incentivo à denúncia de irregularidades e a aplicação efetiva de códigos de ética e de conduta no âmbito da pessoa jurídica" (art. $7^{\circ}$, inc. VIII, Lei $n^{\circ}$ 12.846/13) será considerado na dosimetria das penas culminadas pelo diploma legal (TOMAZETI et al., 2016, p. 2).

A Controladoria-Geral da União (CGU), ciente da relevância que o combate à corrupção tem em nosso país e das dificuldades da implantação de um programa dessa natureza, criou o Programa de Integridade Diretrizes para Empresas Privadas, de característica orientativa, cuja observância é importante para um desenvolvimento mais seguro das atividades pelas organizações.

Pautada pelo Programa de Integridade indicado pela CGU, a presente pesquisa objetiva apresentar um plano com indicadores de práticas de integridade no processo de captação de recursos de monitoramento do histórico de financiadores, patrocinadores e doadores nas relações dessa natureza em organizações do Terceiro Setor (TS). 
O TS é um setor com presença econômica considerável em países do mundo todo, em crescente ascensão, e que no Brasil desempenha um papel relevante no desenvolvimento da sociedade, estabelecendo relacionamentos dos mais variados e estando sujeito aos mais diversos riscos operacionais, segundo pesquisa desenvolvida pelo Johns Hopkins Center for Civil Society Studies (2013). Por sua vez, a escolha pela área de captação de recursos dentro dessas organizações se justifica, conforme se verá adiante, por ser uma área vital para organizações dessa natureza, em que há uma exposição considerável.

Nesse contexto, este relato buscou evidenciar os controles à luz da Teoria da Dependência de Recursos com uma proposta de Programa de Integridade voltado para uma política de captação de recursos para o TS. O estudo foi desenvolvido com uma introdução ao tema, buscando descrever o contexto da realidade; em seguida, uma revisão da literatura, apresentando as teorias.

Espera-se, assim, que esse plano de indicadores de práticas de integridade possa auxiliar essas organizações a auferir mais recursos e se distanciar de eventuais riscos a que estejam expostas pelo desenvolvimento comum de suas atividades.

\section{CONTEXTO E REALIDADE INVESTIGADA}

A evolução histórica do TS permite resumir que é um setor com particularidades, influenciado pela sociedade e pelas diretrizes governamentais. Por esse motivo, exige uma gestão diferenciada dos modelos tradicionais e que, muitas vezes, as próprias organizações do TS ainda não os absorveram, tornando-se deficitárias nesse sentido.

Difere de um modelo de gestão estratégica comum adotado pelas organizações com fins lucrativos, como observa Tenório (2006, p. 1146):

Quanto ao par gestão estratégica e gestão social, eles significarão que o primeiro atua determinado pelo mercado, portanto, é um processo de gestão que prima pela competição, onde o outro, o concorrente, deve ser excluído e o lucro é o seu motivo. Contrariamente, a gestão social deve ser determinada pela solidariedade, portanto, é um processo de gestão que deve primar pela concordância, onde o outro deve ser incluído e a cooperação o seu motivo. Enquanto na gestão estratégica prevalece o monólogo - o indivíduo; na gestão social deve sobressair o diálogo - o coletivo. 
Com o conhecimento da administração dessas organizações, será possível identificar os fatores de compliance nela envolvidos, pois, como Cabral (2015, p. 135) menciona:

Os desafios e as tendências contemporâneos impostos à gestão suscitam, particularmente para as OTS, uma análise de suas práticas, baseada na sua origem, objetivos e peculiaridades de organizações instituídas, para a realização de uma missão em um espaço que se publiciza, a fim de agregar interesses, representações e expectativas de grupos e da sociedade.

Englobam-se assim todos os agentes envolvidos no processo da organização em atingir seus objetivos; destacam-se, no entanto, usuários internos e externos e com interesses que precisam ser conciliados.

A interação entre os setores requer autonomia individual entre eles até mesmo para a concretização de suas ações. Os processos decisórios devem ser compartilhados. Quando essas articulações não ocorrem, o que se verifica é a perda do sentido de setor dentro do contexto e, consequentemente, o não cumprimento de seus objetivos organizacionais.
Uma vez instituídas, a manutenção das organizações dessa natureza é um desafio, isso porque, apesar de desenvolverem atividades de responsabilidade do Estado, este não tem condições de prover recursos financeiros a todas as organizações, obrigando-as a buscar fontes de recursos no setor privado. De acordo com os autores, a interação necessária entre os setores não existe, o que compromete a efetividade das atividades que essas organizações executam.

Entendem Scheunemann e Rheinheimer (2013, p. 34) que a integração do TS e dos demais setores é uma estratégia importante para que haja mudança efetiva no contexto social em que está envolvida a organização do TS.

É possível entender a intencionalidade de integrar novos agentes dos diferentes setores como uma estratégia de proximidade, que interfere de forma mais direta e sensível nas condições de vida da população. O desafio dessa parceria entre os diferentes setores pode vir a se constituir uma estratégia para a garantia e a implementação das políticas de assistência social como direito (SCHEUNEMANN; RHEINHEIMER, 2013, p. 34). 
Há, portanto, necessidade de envolvimento de todos os setores para que os objetivos das organizações do TS possam ser atingidos, e isso tem se mostrado uma tarefa desafiante, pois os demais setores muitas vezes requerem que seu papel naquele contexto esteja evidenciado.

As organizações do TS estão assim envolvidas em um ambiente diversificado, complexo e dinâmico, e que exige uma gestão diferenciada no sentido de atender eficientemente a toda essa demanda.

Identificadas essas necessidades, Tachizawa (2014, p. 133) propõe um modelo de gestão voltado às organizações do TS, do qual é possível observar que os aportes de recursos financeiros fazem parte das decisões estratégicas das organizações.

Esse nível de decisão organizacional corresponde ao Planejamento Estratégico (PE), que:

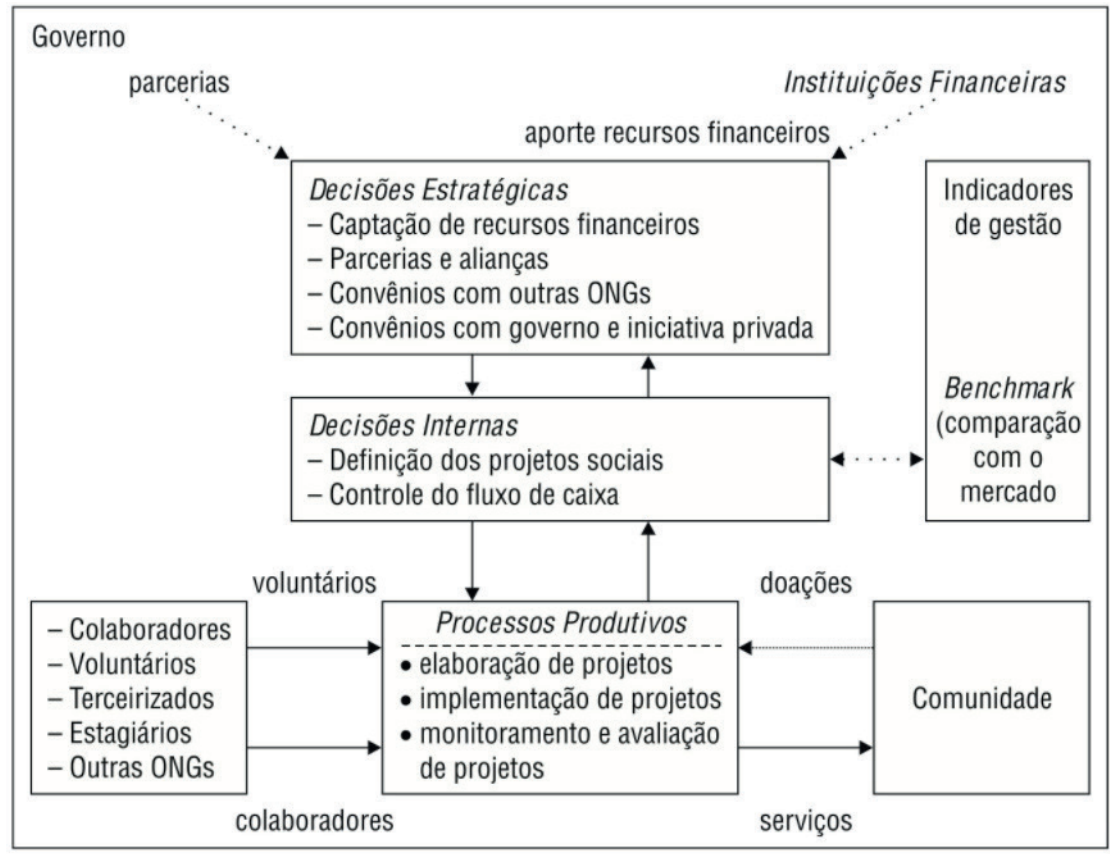

FIGURA 1 - Proposta de modelo de gestão para organizações do TS Fonte: Tachizawa, 2014, p. 135. 
[...] é o processo por meio do qual uma organização estabelece sua identidade organizacional, analisa o seu ambiente de negócio (interno e externo, atual e futuro) e elabora as linhas de ação (ditas estratégias), a fim de aumentar as probabilidades de sucesso (sobrevivência, atendimento de seus objetivos e crescimento sustentável) (GOMES; GOMES, 2014, p. 176).

Percebe-se assim que o processo de captação de recursos dentro de uma organização do TS faz parte de seu planejamento estratégico e deve estar alicerçado sobre todo o ambiente em que opera. Ressalta-se que o contexto externo repercutirá nas linhas de ações internas da organização, que deverá adaptá-las para conquistar seus objetivos, entre eles o de captação de recursos. Isso evidencia bem a dinâmica defendida pela Teoria de Dependência dos Recursos.

Ainda nesse nível decisório, a missão institucional deve estar clara para que as direções adotadas sejam as mais acertadas e que de fato contribuam para o alcance dos objetivos da organização. Como é colocado no modelo proposto por Tachizawa (2014), o intercâmbio de informações entre os níveis de decisões estratégicas e operacionais possi- bilita a verificação contínua do andamento e dos reflexos das ações desenvolvidas, permitindo ajustes constantes.

Tem-se assim que o modelo de gestão das organizações do TS deve ser dinâmico no sentido de abranger ações advindas de outros setores da economia, sem, no entanto, perder sua autonomia evidenciada pela sua missão institucional. No que se refere à captação de recursos, como se verá mais detalhadamente, ela faz parte das decisões estratégicas em que a conciliação de interesses deve ser priorizada conforme preceitua a Teoria de Dependência de Recursos, uma vez que impacta na própria sustentabilidade da organização.

\section{REVISÃO DA LITERATURA}

\section{Teoria da dependência de}

recursos

Conforme se verá mais adiante, a atividade de captação de recursos é de grande relevância para uma organização do TS, isso porque ela depende dos recursos que recebe para desenvolver suas atividades e alcançar seus objetivos.

A Teoria da Dependência de Recursos explica como funciona a dinâmica de 
uma organização que depende diretamente dos recursos que aufere, como é o caso das organizações do TS.

Rosseto e Rosseto (2005, p. 8), em um trabalho de visão complementar comparando a Teoria Institucional e a Dependência de Recursos, indicam que esta considera o papel ativo dos gestores no processo de captação de recursos e na modelagem da gestão interna para o alcance de seus objetivos. Vejamos:

A perspectiva da Dependência de Recursos reconhece os efeitos do ambiente sobre os resultados das estratégias, mas também se concentra no papel da gerência em captar recursos para obter performance satisfatória. A capacidade organizacional para obter recursos vitais e a negociação e o relacionamento interorganizacional também constituem duas atividades fundamentais nesta perspectiva que admite que certas mudanças no meio ambiente ocorrem, em parte, pela determinação dos administradores organizacionais, porque estes se preocupam em compatibilizar as características do ambiente aos interesses específicos das suas organizações (ROSSETO; ROSSETO, 2005, p. 8).
A Teoria da Dependência de Recursos teve como precursores Jeffrey Pfeffer e Gerald R. Salancik, autores da obra The External Control of Organizations de 1978. De acordo com essa teoria, todas as organizações dependem de algum elemento de natureza externa, e o nível de dependência dependerá da qualidade do intercâmbio entre os ambientes interno e externo, que, por sua vez, são reflexo do perfil da gestão organizacional adotada.

\begin{abstract}
As organizações se tornam dependentes de recursos fornecidos pelas outras organizações, criando assim uma rede interorganizacional de dependência de recursos (PFEFFER; SALANCIK, 2003, p. XIX-XX, tradução nossa).
\end{abstract}

Assim, o ambiente externo é relevante para a organização, pois a influencia; no entanto, a organização precisa desenvolver estratégias internas que garantam maior autonomia na defesa de seus interesses dentro do processo de interação com o meio externo para que haja coalisões benéficas para todos os envolvidos.

A Teoria da Dependência de Recursos já foi aplicada por Lima, Ramos e Castello (2012) em duas organizações do TS para 
compreender as relações de dependência dessas organizações e seus mecanismos de sobrevivência. Os resultados indicam que essas organizações são totalmente dependentes de recursos externos, embora não sejam submissas a esses contextos externos. Concluiu-se também que fontes de recursos variadas indicam menor dependência a cada uma delas.

Outro trabalho com hipótese fundamentada na Teoria da Dependência de Recursos foi desenvolvido por Rocha, Moura e Reis (2011), em que os autores buscaram avaliar o impacto exercido pela dependência de recursos essenciais advindos de fornecedores nas medidas de seus processos internos relacionados à Governança Corporativa. Os resultados confirmaram a hipótese de que:

[...] quanto maior a dependência de fornecedores de recursos vitais para organização, mais a gestão entenderia que as práticas de Governança Corporativa cumpririam o papel de conciliar os diversos interesses que envolvem a organização e, consequentemente, garantiriam o fluxo de insumos necessários à continuidade da empresa (ROCHA; MOURA; REIS, 2011, p. 31).
Daí percebe-se que os mecanismos de Governança Corporativa adotados por uma organização afetam os insumos que ela recebe; consequentemente, ela pode administrá-los de maneira a garantir sua sustentabilidade.

No TS, os recursos financeiros fazem parte de seu insumo essencial para a manutenção de suas atividades, e a Teoria da Dependência de Recursos se aplica a essas, uma vez que representa bem a realidade dessas organizações, na medida em que elas precisam adotar procedimentos internos compatíveis com o meio em que estão inseridas para extrair dele os maiores benefícios possíveis e que sejam compatíveis com os anseios de ambos os lados.

Assim, o gestor de uma organização do TS precisa ter autonomia e clareza na missão institucional determinada para que essa dependência de recursos externos não desvirtue sua razão de existir, ao mesmo tempo que possa conciliar os interesses e crescer de forma sustentável.

Por fim, o ambiente externo será afetado por organizações do TS e o intercâmbio construtivo entre ambos é o ponto de equilíbrio e de sucesso em que se fundamenta essa Teoria. A seguir, trataremos dos aspectos relacionados à gestão efetiva desenvolvida pelas organizações do TS. 


\section{Visão geral acerca dos controles} internos

A composição dos subitens a seguir dedicados ao tema de controles internos está embasada nas práticas determinadas pelo Committee of Sponsoring Organizations of the Treadway Commission (Coso), uma organização constituída em 1985 por cinco grandes instituições profissionais americanas: a American Accounting Association (AAA), o American Institute of Certified Public Accountants (AICPA), o Financial Executives International (FEI), o Institute of Internal Auditors (IIA) e o Institute of Management Accountants (IMA). A missão do Coso é fornecer liderança de pensamento de quadros abrangentes e orientação sobre gestão de risco empresarial, controle interno e dissuasão de fraude projetados para melhorar o desempenho organizacional e a governança e reduzir a extensão da fraude nas organizações.

Dentro do TS, o papel dos controles internos no processo de gestão é explorado pelo Instituto Brasileiro de Governança Corporativa (IBGC) juntamente com o Grupo de Institutos Fundações e Empresas (GIFE), que estipulam como melhor prática:
O executivo principal, auxiliado pelos demais órgãos de controle vinculados ao Conselho, é responsável pela elaboração e proposição para aprovação de sistemas de controle internos que monitorem o cumprimento dos processos operacionais e financeiros, assim como os riscos de não conformidade. A eficácia de tais sistemas deve ser revista, no mínimo, anualmente. Esses sistemas de controles internos deverão também estimular que os órgãos da administração encarregados de monitorar e fiscalizar adotem atitude preventiva, prospectiva e proativa na minimização e antecipação de riscos (IBGC; GIFE, 2014, p. 56).

O conhecimento dos controles internos é necessário por ser base de qualquer Programa de Integridade, como se verá adiante.

Para conhecer o processo de gestão de uma organização, faz-se necessário colher informações advindas de seus controles.

O instrumento de gestão que permite acompanhar e criticar o desempenho das atividades, proteger os ativos, disciplinar o relacionamento dos agentes de execução com as atividades e orientar 
a elaboração de informação confiável,

é, normalmente, denominado controle (CFC, 2007, p. 87).

De acordo com a aplicação e a abrangência dos controles, eles podem ser internos ou externos:

O controle, quando executado de forma permanente no âmbito interno da entidade e voltado para o aperfeiçoamento da organização e segurança do patrimônio, é denominado controle interno. Quando executado de fora para dentro e, normalmente, por entidade reguladora ou fiscalizadora, é denominado controle externo (CFC, 2007, p. 87).

Nessa linha de visão, o Coso dá ao controle interno uma definição abrangente, trata-o como um processo, que envolve aspectos relacionados aos indivíduos, além de todas as operações necessárias para que a organização atinja seus propósitos. Vejamos:

Controle interno é um processo conduzido pela estrutura de governança, administração e outros profissionais da entidade, e desenvolvido para proporcionar segurança razoável com respeito à realização dos objetivos relacionados a operações, divulgação e conformidade (COSO, 2013, p. 6).

Diante do exposto, entende-se assim que os controles internos são mecanismos adotados pela organização para orientá-la em sua gestão, seja na mitigação dos riscos, seja nos processos decisórios inerentes ao desenvolvimento de suas atividades.

Para Schmidt, Santos e Martins (2014, p. 36), os controles devem buscar: reconciliações periódicas, ou seja, o confronto entre os registros de ativos físicos e contas contábeis com os respectivos registros físicos; avaliação para a verificação de que os ativos estão registrados de acordo com os princípios contábeis vigentes; proteção física dos bens que devem estar sob a guarda de seus responsáveis; conferência da exatidão e da fidelidade dos dados contábeis, pois os registros contábeis devem corresponder à realidade do fato e precisam ser efetuados em seu tempo; promoção da eficiência operacional, que deve estimular a todo tempo a eficiência operacional; estímulo à obediência das diretrizes administrativas estabelecidas, pois os procedimentos devem ser compatíveis com os padrões estabelecidos pela 
organização; e implantação de projetos de Governança Corporativa, por meio dos quais as organizações obtêm certificações. É desse universo de controles que o sucesso de um Programa de Integridade depende.

Observa-se que os controles internos exercem um papel no processo de subsidiar as decisões relacionadas ao gerenciamento do risco. Mesmo diante disso, uma pesquisa da KPMG (2016, p. 13) revela que

um motivo encontrado pelos profissionais da KPMG ao redor do mundo é que as empresas não estão investindo em controles mais consistentes contra fraudes devido à adversidade econômica.

Se setores que atuam na busca de lucro no desenvolvimento de suas atividades não estão investindo em controles internos adequados devido à adversidade econômica, os controles internos do TS podem vir a ser ainda mais sensíveis, pois essas organizações muitas vezes não possuem recursos para aplicá-los em tais fins. Isso acaba por deixá-las mais expostas a riscos, uma vez que, sem os controles que seriam necessários para o desenvolvimento de suas atividades, acabam executando as tarefas de forma mais simples, sem se aterem ao todo, e isso pode resultar em descontrole e perdas.

Conclui-se assim que os controles internos, além de auxiliarem a organização a atingir os seus objetivos, também a protegem contra riscos operacionais comuns. "Esses objetivos dos controles procuram criar meios para a prevenção de erros e a detecção de qualquer irregularidade nas atividades de uma entidade" (SCHMIDT; SANTOS; MARTINS, 2014, p. 37).

\section{Pilares do programa de integridade}

Tecidas as considerações acerca de controles internos, bem como a política de captação de recursos existentes no TS, o entendimento do que vem a ser um Programa de Integridade voltado à gestão dos financiadores pode ser então explorado.

Programa de Integridade é um programa de compliance específico para prevenção, detecção e remediação dos atos lesivos previstos na Lei 12.846/2013, que tem como foco, além da ocorrência de suborno, também fraudes nos processos de licitações e execução de contratos com o setor público (CGU, 2015, p. 6). 
Essa afirmação oderia se ater apenas à adoção de um programa dessa natureza para a gestão dos recursos advindos do poder público; entretanto, com o advento da Lei n. 13.019 de 2014, as transferências do setor público para as organizações do TS já recebem o amparo legal para esse tipo de controle. Busca-se então a gestão dos recursos em geral, ou seja, advindos do setor público ou do privado.

O termo compliance referenciado no conceito de Programa de Integridade:

Vem do verbo em inglês "†o comply", que significa "cumprir, executar, satisfazer, realizar o que the foi imposto", ou seja, compliance é o dever de cumprir, estar em conformidade e fazer cumprir regulamentos internos e externos impostos às atividades da instituição (ABBI; FEBRABAN, 2009, p. 8).

Frise-se "regulamentos internos e externos impostos às atividades da instituição", as regulamentações externas podem ser mensuradas, uma vez que decorrem de ordenamentos legais, além das determinações com os demais stakeholders e as internas também, com o mapeamento dos processos em que a organização incorre.
É, portanto, possível a mensuração correta dos riscos aos quais ela está sujeita e a adequação a um programa de compliance consistente.

De acordo com a CGU, o Programa de Integridade sugerido possui cinco pilares:

$1^{\circ}$ - Comprometimento e apoio da alta direção:

O apoio da alta direção da empresa é condição indispensável e permanente para o fomento a uma cultura ética e de respeito às leis e para a aplicação efetiva do Programa de Integridade (CGU, 2015, p. 6).

Entende-se, assim, que o exemplo da alta administração é importante para a disseminação e a manutenção da cultura e dos valores da organização. Se os colaboradores de níveis hierárquicos inferiores de uma organização percebem que o discurso advindo da alta administração não condiz com suas práticas, eles não se sentem motivados ou estimulados a incorporarem as práticas que só são discursadas, mas não vivenciadas.

$2^{\circ}$ - Instância responsável pelo Programa de Integridade: 
Qualquer que seja a instância responsável, ela deve ser dotada de autonomia, independência, imparcialidade, recursos materiais, humanos e financeiros para o pleno funcionamento, com possibilidade de acesso direto, quando necessário, ao mais alto corpo decisório da empresa (CGU, 2015, p. 6).

A organização precisa estabelecer uma equipe responsável pela implantação e gestão do Programa de Integridade, revestida de imparcialidade e de autonomia para desempenhar eficientemente suas atribuições e promover as mudanças necessárias.

$3^{\circ}$ - Análise de perfil e de riscos: de acordo com Damodaran (2009, p. 299),

toda empresa enfrenta riscos, e a primeira etapa na gestão de riscos consiste em elaborar uma lista de todos os riscos que enfrenta e obter uma medida da exposição a cada um deles.

A organização deve assim fazer uma autoanálise do setor em que atua e, a partir da identificação das variáveis, planificar os riscos aos quais está sujeita. $4^{\mathrm{o}}$ - Estruturação das regras e dos instrumentos: a disseminação das práticas adotadas pela organização só é possível com a formalização e a divulgação de seu conteúdo por meio de códigos, comunicados internos ou de qualquer outro meio; isso é importante para a legitimação da consolidação da cultura organizacional.

$5^{\circ}$ - Estratégias de monitoramento contínuo: ações necessárias para o acompanhamento da eficácia dos controles estabelecidos. Somente o acompanhamento evidenciará a necessidade ou não de ajustes no curso do Programa de Integridade.

\section{Programa de integridade e políticas de doações}

Ainda dentro do Programa de Integridade proposto pela CGU, observa-se destaque para a gestão de doações de organizações privadas para terceiros:

Uma empresa comprometida com a integridade nos negócios deve estar atenta para o histórico daqueles que receberão seus financiamentos, patrocínios ou doações, para evitar possíveis associações de sua imagem com fraudes ou corrupção (CGU, 2015, p. 19). 
De acordo com a recomendação da CGU, as organizações privadas deverão ter cuidado com a política de doações adotada para que ela não se envolva com organizações que não sejam sérias em seus propósitos.

Baseando-se nessa orientação, é possível que as organizações do TS se organizem no sentido de atender ao que demanda seus patrocinadores; no entanto, elas também poderão se estruturar de forma a afastar possíveis patrocinadores que estejam envolvidos em atos fraudulentos ou corruptos, o que poderia comprometer a sua imagem diante de outros financiadores.

A partir dos procedimentos internos de captação de recursos, elencaremos os cuidados peculiares a cada espécie de relação jurídica comumente estabelecida:

Receitas próprias: No que tange ao recebimento de recursos decorrentes de vendas de produtos e serviços, a cautela que se deve ter, segundo a Ordem dos Advogados do Brasil (OAB) (2011, p. 29), está relacionada a formalidades legais, a registros em órgãos competentes, bem como a demais obrigações relacionadas. Logicamente, reforçando as disposições legais, "a comercialização de mercadoria deve estar prevista no Estatuto Social como um meio para a sustentação financeira da entidade" (OAB, 2011, p. 29).
Receitas de doações e contribuições: No que se refere a esse tipo de recebimentos, a OAB (2011, p. 10) alerta quanto ao seu tratamento. Assim, ao analisar o recebimento de doações com encargo, as organizações de Terceiro Setor devem observar com clareza qual a intenção e as contrapartidas, de fato, pretendidas pelo doador. Ressalta-se que, de acordo com a natureza jurídica dessa relação, os encargos deverão ser cumpridos.

Ainda no âmbito das doações, como são comuns na rotina das organizações do TS, muitas vezes os recursos recebidos advindos de outras atividades são classificados equivocadamente como doações. Por essa razão, adverte a OAB (2011, p. 12) de que há necessidade de formalização, bem como a observação de todos os seus aspectos.

Por fim, cabe ressaltar que, de acordo com a Lei n. 10.705/00 sobre as doações, há incidência de Imposto sobre Transmissão de Bens por Causa Mortis e Doação (ITCMD) que tem como contribuinte e responsável tributário o donatário. Assim, as organizações do TS devem atentar para a legislação pertinente no momento da realização ou recebimento de doação, inclusive no que se refere à sua possível isenção ou imunidade. 
Receitas de auxílios e subvenções: As subvenções são tratadas pela Lei n. 4.320/64, em que é possível verificar a limitação estabelecida pelo legislador; sendo assim, não são todas as instituições que podem receber recursos dessa natureza, restringindo-se àquelas que prestam serviços essenciais de assistência social, médica e educacional. A necessidade de observância dos preceitos legais é esclarecida por Oliveira (2013, p. 495):

[...] que para que a instituição seja destinatária de recursos públicos, imprescindível é a análise prévia da situação de funcionamento da instituição. Logo, ainda que haja solicitação de destinação de recursos orçamentários para auxílio a determinada instituição, imprescindível é que tenha havido exame anterior das condições de funcionamento e que tenham sido julgadas satisfatórias. Mesmo porque, se assim não for, sequer o recurso pode ser destinado.

As organizações do TS devem então verificar seus procedimentos internos para conferir se estão de acordo com as determinações legais, para não incorrer no risco de receber recursos sem terem direito.

Receitas de parcerias: As parcerias de- vem atentar às regras estabelecidas na Lei n. 13.019/2014, também conhecida como Marco do Terceiro Setor, que normatiza as relações entre a administração pública e as organizações da sociedade civil.

A Lei 13.019/2014, estabelece o regime jurídico das parcerias entre a administração pública e as organizações da sociedade civil, em regime de mútua cooperação, para a consecução de finalidades de interesse público e recíproco, mediante a execução de atividades ou de projetos previamente estabelecidos em planos de trabalho inseridos em termos de colaboração, em termos de fomento ou em acordos de cooperação; define diretrizes para a política de fomento, de colaboração e de cooperação com organizações da sociedade civil; e altera as Leis n. 8.429, de 2 de junho de 1992, e n. 9.790, de 23 de março de 1999 que aborda sobre os convênios firmados entre instituições sem fins lucrativos e o poder público.

Também conhecida como Marco Regulatório das Organizações da Sociedade Civil, estabelece os Termos de Fomento que são os instrumentos das parcerias propostas pelas organizações da sociedade civil para realização de finalidades de interesse público e os Termos de Colaboração 
que são os instrumentos das parcerias estabelecidas pela Administração Pública. Por Acordos de Cooperação entende-se as parcerias sem recursos financeiros.

Para Grazzioli et al. (2016, p. 32):

Apesar do nome conferido à nova legislação, é importante esclarecer que ela não lida com todas as questões jurídicas relativas às organizações não governamentais e, portanto, não se trata de um novo marco regulatório, pois ela atinge apenas a esfera da transferência de recursos públicos para as entidades e outras formas de diretas de parcerias.

Trata-se de uma Lei com forte menção ao controle de resultados, visando análise de impacto, transparência quanto a divulgação de informações relacionadas às parcerias estabelecidas, prestação de contas e planejamento com que as ações deverão ser desenvolvidas pelas organizações.

\section{CONSIDERAÇÕES FINAIS}

Considerando o que foi exposto, à luz das teorias, é possível fazer uma proposta de um Programa de Integridade voltado à captação de recursos com os procedimentos de monitoramento contínuo estruturado com regras e procedimentos de controle para implementar políticas sobre patrocínios e doações: na base da estrutura está a missão da organização, uma vez que ela é a responsável pelo direcionamento das ações da área de captação de recursos. A área de captação de recursos deverá compreender a missão e, pautada por ela, direcionar seus esforços para as fontes de recursos compatíveis com a missão da organização, ou seja, a área de captação de recursos deverá localizar, entre as fontes de captação de recursos disponíveis, aquelas que estejam em consonância com a missão da organização.

Identificadas as fontes convenientes, o processo de relacionamento deve observar os procedimentos em geral cabíveis pela mensuração dos riscos. Por fim, com os riscos devidamente identificados, a organização precisa implantar os controles internos necessários para a efetiva concretização de sua missão:

$\mathrm{O}$ alcance do estudo restringe-se ao processo de captação de recursos em uma organização do TS, e, como vimos, a gestão dessas organizações apresenta peculiaridades que devem ser observadas. Pesqui- 


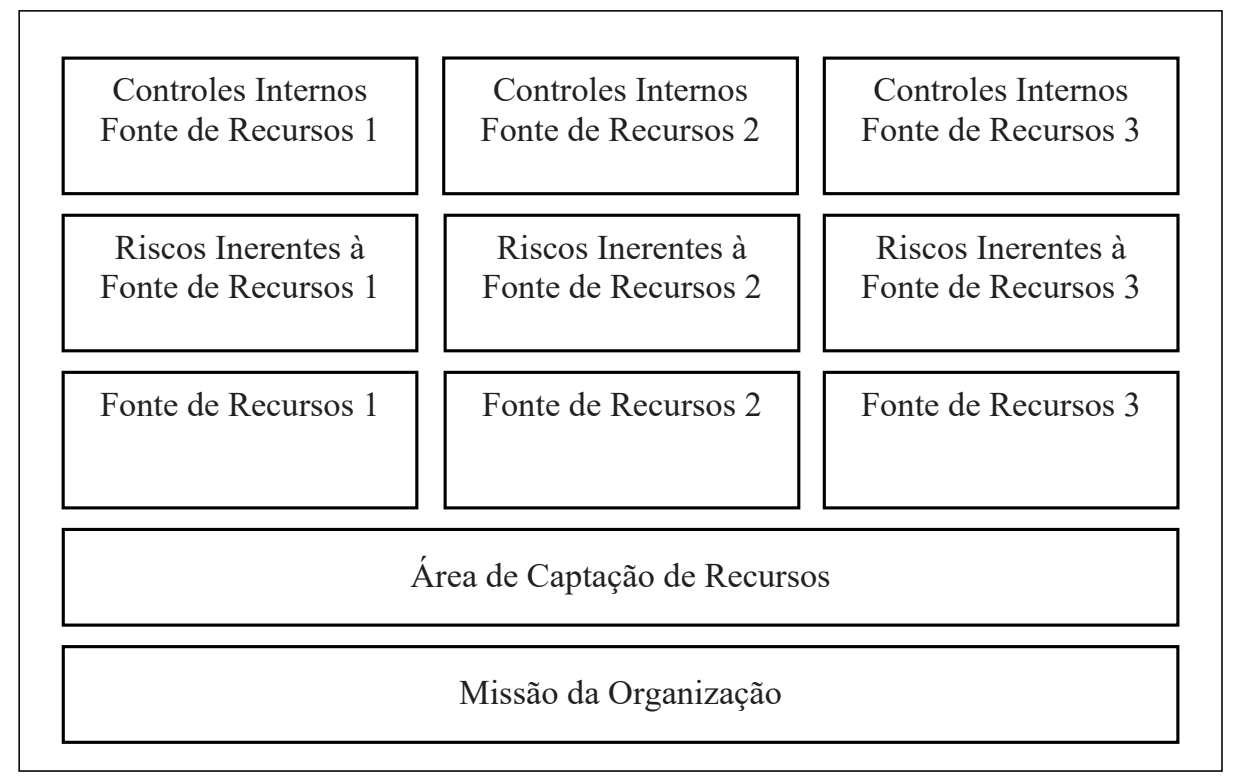

FiguRA 2 - Proposta de programa de integridade voltado à captação de recursos Fonte: Elaborada pelas autoras.

sas que aprofundem práticas de integridade voltadas a outras áreas nesses tipos de organizações são essenciais para que possa ser oferecido um modelo mais abrangente. Além disso, a conciliação desses modelos é fundamental para que possam ser adotados simultaneamente.
INTEGRITY PRACTICES IN THE PROCESS OF RAISING FUNDS FOR THIRD SECTOR ORGANIZATIONS

\section{ABSTRACT}

The organizations that compose the third sector are allies of the State in meeting public needs, and for this reason play a relevant role in society. Fundraising in these types of organizations is one of its main components of management, since they are not for profit, depending on resources coming from third parties to maintain their activities. Within the pro- 
cess of attracting resources, third sector organizations are exposed to a wide range of risks that may compromise their legal nature and sustainability. Internal control mechanisms are the answer to abolish or to minimize to operational risks that organizations of this nature have to face in the common performance of their activities. This research, based on a bibliographic review about the dependence of resources and internal controls, seeks to offer a model of Integrity Practices Program formatted from the intervention in an organization, in which there is dimensioning of the specific risks directed to the process of fundraising, to subsidize third sector organizations with specific information so that they can operate more safely and comply with the legislative apparatus they are subject.

\section{KEYWORDS}

Fundraising. Third Sector. Operational risks. Integrity practices.

\section{REFERÊNCIAS}

ASSOCIAÇÃO BRASILEIRA DE BANCOS INTERNACIONAIS (ABBI); FEDERAÇÃO BRASILEIRA DE BANCOS (FEBRABAN). Função de compliance. 2009. Disponível em: <http://www.abbi.com.br/ download/funcaodecompliance_09.pdf>. Acesso em: 21 abr. 2017.
BRASIL. Congresso Nacional. Senado Federal. Comissão Parlamentar de Inquérito destinada a apurar, no prazo de 180 (cento e oitenta) dias, as denúncias veiculadas a respeito da atuação irregular de organizações não governamentais - ONGs. Brasília, DF, 2010. Disponível em: <http://www2.senado.leg.br/bdsf/ handle/id/194594>. Acesso em: 6 maio 2017.

CABRAL, E. H. de S. Terceiro setor: gestão e controle social. 2. ed. São Paulo: Saraiva, 2015.

CERVO, A. L.; BERVIAN, P. A.; SILVA, R. da. Metodologia científica. 6. ed. São Paulo: Pearson, 2007.

CONSELHO FEDERAL DE CONTABILIDADE (CFC). Manual de Procedimentos Contábeis para Fundações e Entidades de Interesse Social. Brasília, DF:CFC, 2007.Disponível em: <https://www2.mppa.mp.br/sistemas/ gcsubsites/upload/56/entidadesdeinteresse socialeterceirosetor-100819051041-phpa pp01(1).pdf>. Acesso em: 27 maio 2017.

COMMITTEE OF SPONSORING ORGANIZATIONS OF THE TREADWAY COMMISSIO (COSO). Controle Interno: estrutura integrada. Tradução Instituto dos Auditores Internos do Brasil (IIA) e PricewaterhouseCoopers (PwC). 2013. Disponível em: <http:// www.iiabrasil.org.br/new/2013/downs/ coso/COSO_ICIF_2013_Sumario_Executivo. pdf $>$. Acesso em 27 maio 2017. 


\section{CONTROLADORIA GERAL DA UNIÃO} (CGU). Programa de integridade: diretrizes para empresas privadas. Brasília, 2015. Disponível em: <http://www.cgu.gov.br/ Publicacoes/etica-e-integridade/arqui vos/programa-de-integridade-diretrizes para-empresas-privadas.pdf $>$. Acesso em: 27 maio 2017.

CRUZ, C. M.; ESTRAVIZ, M. Captação de diferentes recursos para organizações sem fins lucrativos. 2. ed. São Paulo: Global, 2003.

DAMODARAN, A. Gestão estratégica do risco: uma referência para a tomada de riscos empresariais. Porto Alegre: Bookman, 2009.

GOIS, V. S.; SANTOS, A. E.; ROCHA, I. M. M. da. Marco normativo anticorrupção: desafios para implantação de compliance. Revista da Controladoria-Geral da União, Brasília, v. 8, n. 12, jan-jun. 2016. Disponível em: <https://ojs.cgu.gov.br/index.php/ Revista_da_CGU/article/view/11/19>. Acesso em: 27 maio 2017.

GOMES, L. F. M.; GOMES, C. F. S. Tomada de decisão gerencial: enfoque multicritério. 5. ed. São Paulo: Atlas, 2014.

GRAZZIOLI, A. et al. Organizações da sociedade civil: associações e fundações. Constituição, funcionamento e remuneração de dirigentes. São Paulo: EDUC, 2016.
INSTITUTO BRASILEIRO DE GOVERNANÇA CORPORATIVA (IBGC); GRUPO DE INSTITUTOS FUNDAÇÕES E EMPRESAS (GIFE). Guia das melhores práticas de governança para fundações $e$ institutos empresariais. 2. ed. São Paulo: IBCG, 2014. Disponível em: <https:// www.fbb.org.br/images/Documentos/ Guia_das_Melhores_Prticas.pdf>. Acesso em: 27 maio 2017.

JOHNS HOPKINS CENTER FOR CIVIL SOCIETY STUDIES. The state of global civil society and volunteering: Latest findings from the implementation of the UN nonprofit handbook. Compoarative nonprofit sector working paper, n. 49, p. 1-15. mar. 2013. Disponível em: <http:// ccss.jhu.edu/wp-content/uploads/down loads/2013/04/JHU_Global-Civil-SocietyVolunteering_FINAL_3.2013.pdf $>$. Acesso em: 27 maio 2017.

KPMG. Perfil global do fraudador: A tecnologia viabiliza e os controles deficientes estimulam a fraude. [S.1.], 2016. Disponível em: <https://assets.kpmg.com/content/ $\mathrm{dam} / \mathrm{kpmg} / \mathrm{br} / \mathrm{pdf} / 2016 / 09 /$ br-perfildo-fraudador-2016.pdf>. Acesso em: 20 abr. 2017. 
LIMA, M. A. S.; RAMOS, N. R. G.; CASTELLO, R. do N. Organizações do terceiro setor e a teoria da dependência de recursos: um estudo de Benevides, na Amazônia brasileira, e Ilha de Santiago, em Cabo Verde, na África. In: CONGRÈS TRANSFORMARE, 2., 2012, Paris. Anais... Paris: Conservatoire National des Arts et Metiers, 2012. p. 1-16. Disponível em: <http://www.transformare. adm.br/anais/Rebecca-do-NascimentoArtigo-tranformare-\%281\%29-2.pdf > . Acesso em: 27 maio 2017.

MAGALHÃES, J. M. R. Aspectos relevantes da lei anticorrupção empresarial brasileira (Lei n. 12.846/2013). Revista Controle, Ceará, v. 11, n. 2, p. 24-46, dez. 2013. Disponível em: <https://www.tce.ce.gov. br/edicoes/revista-controle-volumexi-n-2-dezembro-2013/send/211revista-controle-volume-xi-n-2-dezembro$2013 / 2290$-artigo-2-aspectos-rele vantes-da-lei-anticorrupcao-empresarialbrasileira-lei-n-12-846-2013>. Acesso em: 27 maio 2017.

MASCARENHAS, S. A. Metodologia científica. São Paulo: Pearson, 2012.
MINISTÉRIO DA TRANSPARÊNCIA, FISCALIZAÇÃO E CONTROLE (MTFC). Convenção da OCDE contra o suborno transnacional. Brasília, DF, 2016. Disponível em: <http://www.cgu.gov.br/assun tos/articulacao-internacional/conven cao-da-ocde/arquivos/cartilhaocde-2016.pdf>. Acesso em: 27 maio 2017.

OLIVEIRA, R. F. de. Curso de Direito Financeiro. 5. ed. São Paulo: Editora Revista dos Tribunais, 2013.

ORDEM DOS ADVOGADOS DO BRASIL (OAB). Comissão de direito do terceiro setor. captação de recursos para o terceiro setor: aspectos jurídicos. São Paulo, 2011. Disponível em: <http://www.oabsp.org.br/ comissoes2010/direito-terceiro-setor/ cartilhas/REVISaO\%202011Cartilha_ Revisao_2007_Final_Sem\%20desta que\%20de\%20alteracoes.pdf $>$. Acesso em: 27 maio 2017.

PFEFFER, J.; SALANCIK, G. R. The external control of organizations: a resource dependence perspective. 2nd ed. California: Stanford University Press, 2003. 
ROCHA, J. S. da; MOURA, F. V.; REIS, G. M. R. Teoria da dependência de recursos explicando a percepção de governança corporativa de importantes tomadores de decisão. Revista de Contabilidade da UFBA, Salvador, v. 5, n. 3, p. 31-44, set./dez. 2011. Disponível em: <https://reposito rio.ufba.br/ri/bitstream/ri/15354/1/ 6184-18828-1-PB.pdf>. Acesso em: 27 maio 2017.

ROSSETTO, C. R.; ROSSETTO, A. M. Teoria institucional e dependência de recursos na adaptação organizacional: uma visão complementar. RAE-Revista de Administração de Empresas Eletrônica, São Paulo, v. 4, n. 1, jan./jul. 2005. Disponível em: $<$ http://www.rae.com.br/eletronica/ index.cfm? FuseAction=Artigo \& ID $=1869 \&$ Secao $=$ FOR.TE.INS \&Vo lume $=4 \&$ Numero $=1 \&$ Ano $=2005>$. Aces so em: 27 maio 2017.

SCHEUNEMANN, A. V.; RHEINHEIMER, I. Administração do terceiro setor. Curitiba: InterSaberes, 2013.

SCHMIDT, P.; SANTOS, J. L. dos; MARTINS, M. A. dos S. Manual de Controladoria. São Paulo: Atlas, 2014.
TACHIZAWA, T. Organizações não governamentais e terceiro setor: criação de ONGs e estratégias de atuação. 6. ed. São Paulo: Atlas, 2014.

TENÓRIO, F. G. A trajetória do Programa de Estudos em Gestão Social (Pegs). RAP, Rio de Janeiro, v. 40, n. 6, p. 1145-1162, nov./ dez. 2006. Disponível em: <http://www.scie lo.br/pdf/rap/v40n6/11.pdf>. Acesso em: 27 maio 2017.

THEODORO JÚNIOR, H. O contrato e sua função social. 4. ed. Rio de Janeiro: Forense, 2014.

TOMAZETI, R. S. et al. A importância do compliance de acordo com a Lei Anticorrupção. Anais do EVINCI, Curitiba, v. 2, n. 2, p. 297 310, nov. 2016. Disponível em: <http://portaldeperiodicos.unibrasil.com.br/index. php/anaisevinci/article/view/1693/1131>. Acesso em: 13 jun. 2017. 